\title{
(2) OPEN ACCESS \\ Impact of a ban on the open display of tobacco products in retail outlets on never smoking youth in the UK: findings from a repeat cross-sectional survey before, during and after implementation
}

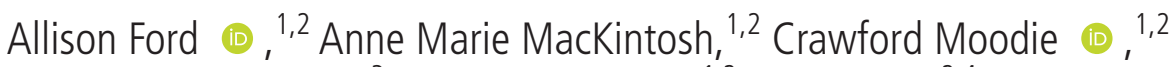 \\ Mirte A G Kuipers (1) , ${ }^{3}$ Gerard B Hastings, ${ }^{1,2}$ Linda Bauld ${ }^{2,4}$
}

${ }^{1}$ Institute for Social Marketing, University of Stirling, Stirling, UK ${ }^{2}$ UK Centre for Tobacco and Alcohol Studies, University of Stirling, Stirling, UK ${ }^{3}$ Department of Public Health, Academic Medical Center, University of Amsterdam, Amsterdam, The Netherlands ${ }^{4}$ Usher Institute, College of Medicine and Veterinary Medicine, University of Edinburgh, Edinburgh, UK

Correspondence to Dr Allison Ford, Institute for Social Marketing, University of Stirling, Stirling FK9 4LA, UK a.j.ford@stir.ac.uk

Received 7 November 2018 Revised 14 March 2019 Accepted 20 March 2019 Published Online First 14 May 2019

\section{ABSTRACT \\ Background In the UK, a ban on the open display of tobacco products at the point of sale (POS) was phased in between 2012 and 2015. We explored any impact of the ban on youth before, during and after implementation.}

Methods A repeat cross-sectional in-home survey with young people aged 11-16 years old in the UK was conducted preban (2011, $n=1373$ ), mid-ban (2014, $n=1205)$ and postban (2016, $n=1213)$. The analysis focuses on the never-smokers in the sample $(n=2953$ in total). Preban, we quantified the associations of noticing cigarettes displayed at POS and cigarette brand awareness with smoking susceptibility. We measured any change in noticing cigarettes displayed at POS, cigarette brand awareness and smoking susceptibility between preban, mid-ban and postban. Postban, we assessed support for a display ban, perceived appeal of cigarettes and perceived acceptability of smoking as a result of closed displays.

Results Preban, noticing cigarettes displayed at POS (adjusted $O R[A O R]=1.97,95 \% \mathrm{Cl} 1.30$ to 2.98 ) and higher brand awareness (AOR=1.15,95\% Cl 1.03 to 1.29 ) were positively associated with smoking susceptibility. The mean number of brands recalled declined from 0.97 preban to 0.69 postban $(p<0.001)$. Smoking susceptibility decreased from $28 \%$ preban to $23 \%$ mid-ban and $18 \%$ postban (p for trend $<0.001)$. Postban, $90 \%$ of never-smokers supported the display ban and indicated that it made cigarettes seem unappealing (77\%) and made smoking seem unacceptable (87\%).

Conclusions Both partial and full implementation of a display ban were followed by a reduction in smoking susceptibility among adolescents, which may be driven by decreases in brand awareness.

\section{INTRODUCTION}

In countries that have introduced comprehensive bans on tobacco advertising, promotion and sponsorship, the retail environment becomes more important for tobacco companies as the display of tobacco products at the point of sale (POS) allows them to showcase their products. ${ }^{1}$ To make the most of this opportunity, they invest heavily in ensuring that tobacco brands are attractively packaged and prominently positioned. ${ }^{2} 3$ A systematic review and meta-analysis found a consistent positive association between POS tobacco promotion or displays and increased smoking and smoking susceptibility among children and adolescents. ${ }^{45}$ Open tobacco displays also evoke positive attitudes among young people, including the perception that displays are 'cool' and attract people to smoke. ${ }^{6}$ As such, requiring tobacco products to be kept out of sight in shops may help to protect youth. ${ }^{7}$ However, there is limited research exploring the impacts of a ban on the open display of tobacco products, hereafter referred to as a 'display ban', on youth.

A display ban was first introduced by Iceland in 2001 , with 20 countries having implemented a ban by $2016 .^{8}$ In the UK a display ban was not introduced for all retailers at the same time. Instead, it was first introduced in large shops (over $280 \mathrm{~m}^{2}$ of retail space) in England in April 2012, in Northern Ireland in October 2012, in Wales in December 2012, and in Scotland in April 2013. The difference in timing between the four countries that comprise the UK was because each was free to implement the display ban when they chose, and in the case of Scotland a legal challenge delayed its introduction. The full ban, covering small shops as well, came into force in April 2015 throughout the UK. ${ }^{9}$ The UK ban stipulates that the tobacco gantry or storage unit must be fully covered to obscure the view of tobacco products completely. Although the rules do not stipulate how units should be covered, most retailers use sliding doors or hanging covers, although curtains are also allowed. When retrieving products the area which can be displayed must not exceed $1.5 \mathrm{~m}^{2}$.

Evidence on the impact of display bans suggests that they may help to contribute to a reduction in adolescent smoking rates. A study found that across six European countries which had implemented a display ban, this measure was associated with a $15 \%$ decrease in the odds of adolescent regular smoking. ${ }^{10}$ Evidence from Australia ${ }^{11}$ and New Zealand ${ }^{12}$ also found a reduction in adolescent smoking rates, but not in Ireland. ${ }^{13}$ However, conducting repeat interviews with a small sample over a short time period may have contributed to the null finding.

Some studies have explored potential mechanisms through which display bans may reduce smoking prevalence. After implementation of a display ban, approximately $40 \%$ of a sample of adolescents in Ireland thought that the removal of tobacco from view in shops made it easier for children not to 
smoke. ${ }^{13}$ Adolescents in Norway ${ }^{14}$ and Australia ${ }^{11}$ recognised fewer tobacco brands after a display ban, and young people in Ireland $^{13}$ and Australia ${ }^{11}$ were less likely to overestimate the smoking prevalence among their peers. A study in England found an association between a display ban and a lower incidence of adolescent regular smokers (ages 11-15) purchasing cigarettes from shops, but no changes in perceived difficulty in purchasing cigarettes from shops. ${ }^{15}$ Another English study, conducted with adolescents (ages 11-16) in Nottingham before the full ban came into force, found that a partial display ban did not result in reduced susceptibility to smoke. ${ }^{16}$

We build on past research by exploring the impacts of a display ban, in a country where it has been phased in over a period of several years, among a UK-wide sample (England, Scotland, Wales and Northern Ireland) of young people aged 11-16 years old before, during and after implementation. Specifically, we aimed to address three research questions: (1) What are the preban associations of noticing cigarettes displayed at POS and cigarette brand awareness with smoking susceptibility? (2) To what extent did noticing cigarettes displayed at POS, cigarette brand awareness and smoking susceptibility change between preban, mid-ban and postban measurements? (3) What were the mid-ban and postban levels of support for the display ban, and did having cigarettes behind closed shutters make cigarettes seem unappealing and smoking seem unacceptable?

\section{METHODS}

\section{Study design}

Data were from waves 6,7 and 8 of the Youth Tobacco Policy Survey, a long-term, repeat cross-sectional study that examines the impacts of tobacco control policies in the UK on young people. Wave 6 was conducted in August-September 2011, before the display ban was introduced. Wave 7 was conducted in August-September 2014, after the ban had been introduced in large shops but prior to it being introduced in smaller shops. Wave 8 was conducted in August-September 2016, 16-17 months after the ban had been fully implemented. A market research company was commissioned to recruit participants, secure participant and parental consent prior to each interview, and conduct the fieldwork. The fieldwork comprised in-home, face-to-face interviews, accompanied by a self-administered questionnaire to gather more sensitive information on smoking behaviour and susceptibility to smoke.

\section{Sample}

The sample comprised young people aged 11-16 years (2011: $\mathrm{n}=1373 ; 2014: \mathrm{n}=1205 ; 2016: \mathrm{n}=1213$ ) drawn from households across the UK, using random location quota sampling. Sampling involved random selection of 92 electoral wards, stratified by Government Office Region and A Classification Of Residential Neighbourhoods classification (a geodemographic classification system that describes demographic and lifestyle profiles of small geographical areas) to ensure coverage of a range of geographical areas and sociodemographic backgrounds. For more information on the sampling and methodology, see elsewhere. ${ }^{17-19}$

\section{Measures}

Sociodemographic characteristics

At each wave age, gender and smoking by parents, siblings (if any) and close friends were obtained. Social grade was determined by the occupation of the chief income earner in the household (ABC1 $=$ middle class, $\mathrm{C} 2 \mathrm{DE}=$ working class $)$. These groupings are based on the widely used UK demographic classifications system derived from the National Readership Survey. Middle class (ABC1) reflects managerial, administrative and professional occupations. Working class (C2DE) reflects skilled and unskilled manual workers, and casual or lowest grade workers.

\section{Cigarette brand awareness}

A single item asked participants to name cigarette brands they had heard of. No prompts were given and a maximum of 10 brands were recorded.

\section{Smoking susceptibility}

Never-smokers were those who indicated that they had never tried or experimented with smoking, not even a few puffs. Susceptibility, defined as the absence of a firm decision not to smoke, ${ }^{20}$ was measured across three items addressing the likelihood that they would (1) be smoking when they are 18, (2) smoke a cigarette at any time during the next year and (3) smoke if one of their friends offered them a cigarette. Response options for each were 'definitely not', 'probably not', 'probably yes' and 'definitely yes'. Never-smokers were classed as non-susceptible if they responded 'definitely not' for all three items, and as susceptible if their response was anything other than 'definitely not' to any of the three items.

\section{Noticing displays}

This was measured via a single item. In 2011, preban, participants were asked: 'In the last month, have you seen cigarette packets being displayed, including on shelves or on the counter?' In the mid-ban and postban survey waves, the item was reworded to make it clear to participants that they were being asked about the open display of cigarette packets: 'In the last month, have you seen cigarette packets being openly displayed, including on shelves or on the counter? By openly displayed, I mean without any shutters or screens covering the packs'. To each question participants could respond 'yes', 'no' or 'don't know'. Those who answered 'yes' were classed as having 'noticed' displays. Given the lack of positive affirmation on noticing, those who answered 'don't know' were combined with the 'no' responses and classed as having 'not noticed'.

\section{Perceptions of, and support for, closed displays}

Three items assessed perceptions of closed displays mid-ban and postban: (1) support for cigarettes being out of sight; (2) perceived appeal of cigarettes; and (3) perceived acceptability of smoking resulting from closed displays. Participants were asked: 'Now I'd like to find out what you think about cigarette packets being hidden behind shutters or screens in shops. Can you read the statements on both sides of this card and give me the number that best describes what you think?' For each item responses were measured on a 5-point scale: (1) shops should have to keep cigarette packs behind closed shutters (1)/shops should be allowed to have cigarette packs visible (5); (2) having cigarette packs behind shutters in shops makes cigarettes seem unappealing (1) or appealing (5); and (3) having cigarette packs behind shutters in shops makes me think that it's NOT OK to smoke (1) or OK to smoke (5).

\section{Statistical analysis}

Data were analysed using SPSS V.23. Descriptive data and bivariate analysis were weighted to standardise by age and gender across survey years. The analysis focused on the 2953 never-smokers (2011: $\mathrm{n}=1025 ; 2014: \mathrm{n}=948 ; 2016: \mathrm{n}=980$ ). 
First, we analysed the 2011 data. Associations between preban measures of susceptibility to smoke and noticing cigarette packets at POS and brand recall were examined using logistic regression to enable the potential influence of demographic and smoking-related variables to be controlled. The control variables were sibling, close friend and parental smoking; age; gender; and social grade.

Second, we analysed changes over time. Bivariate analysis was conducted using the $\chi^{2}$ test to examine potential differences, across survey years, in (1) noticing of cigarette packets at POS and (2) susceptibility to smoke. One-way analysis of variance (ANOVA) was conducted to test for differences in the number of brands recalled across survey years. Within the ANOVA, the Welch's $F$ test was used, as homogeneity of variance assumption was not met for the brand recall data. Additionally, logistic regression was conducted to test for differences across survey years in susceptibility after controlling for smoking-related and demographic variables. The same control variables used to model the 2011 data were included, with survey year added. The mid-ban survey year (2014) was set as the reference category to explore whether susceptibility changed between preban and mid-ban measures and between mid-ban and postban measures. All logistic regressions were conducted on unweighted data as age, gender and social grade were control variables. Age was entered as a categorical variable as the assumptions of linearity of the logit were not met for all analyses. For the categorical age variable, the 'difference' contrast, within SPSS logistic regression, was used to test the influence of each increasing age group relative to all younger ages (eg, 12 vs 11,13 vs $11-12,14$ vs 11-13). In each logistic regression cases were excluded if they had missing data on the dependent variable or any of the independent variables.

Third, we describe mid-ban and postban percentages of support for the display ban, perceived appeal of cigarettes and perceived acceptability of smoking as a result of closed displays. For each item, the percentage who answered codes ' 1 ' or ' 2 ' (indicating support) on the 5-point scale is reported. For each item, those who did not answer (ie, did not provide a score between ' 1 ' and ' 5 ') were treated as missing data.

\section{RESULTS}

\section{Sample description}

After excluding cases that had missing information for smoking status $(n=33), 78 \%(n=2920)$ of the weighted sample were never-smokers (table 1 ). The mean age of never-smokers was 13.17 years $(\mathrm{SD}=1.64)$, with $50 \%(\mathrm{n}=1473)$ male and $57 \%$ $(\mathrm{n}=1648)$ working class (C2DE). Approximately a quarter, 23\% $(n=673)$, were categorised as susceptible to smoke.

Table 1 Sample profile based on unweighted and weighted frequencies

\begin{tabular}{|c|c|c|c|c|c|c|c|c|}
\hline & \multicolumn{4}{|c|}{ Full sample } & \multicolumn{4}{|c|}{ Never-smokers } \\
\hline & \multicolumn{2}{|c|}{ Unweighted } & \multicolumn{2}{|c|}{ Weighted* } & \multicolumn{2}{|c|}{ Unweighted } & \multicolumn{2}{|c|}{ Weighted* } \\
\hline & $\mathbf{n}$ & $\%$ & $\mathbf{n}$ & $\%$ & $\mathbf{n}$ & $\%$ & $\mathbf{n}$ & $\%$ \\
\hline Total & 3791 & 100 & 3788 & 100 & 2953 & 100 & 2920 & 100 \\
\hline \multicolumn{9}{|l|}{ Gender } \\
\hline Male & 1898 & 50 & 1895 & 50 & 1502 & 51 & 1473 & 50 \\
\hline Female & 1893 & 50 & 1892 & 50 & 1451 & 49 & 1448 & 50 \\
\hline \multicolumn{9}{|l|}{ Age } \\
\hline 11 & 719 & 19 & 627 & 17 & 682 & 23 & 596 & 20 \\
\hline 12 & 596 & 16 & 626 & 17 & 548 & 19 & 576 & 20 \\
\hline 13 & 643 & 17 & 639 & 17 & 537 & 18 & 534 & 18 \\
\hline 14 & 658 & 17 & 624 & 16 & 513 & 17 & 487 & 17 \\
\hline 15 & 621 & 16 & 640 & 17 & 396 & 13 & 411 & 14 \\
\hline 16 & 551 & 15 & 630 & 17 & 277 & 9 & 316 & 11 \\
\hline Mean (SD) & \multicolumn{2}{|c|}{$13.40(1.70)$} & \multicolumn{2}{|c|}{$13.51(1.71)$} & \multicolumn{2}{|c|}{$13.08(1.63)$} & \multicolumn{2}{|c|}{$13.17(1.64)$} \\
\hline \multicolumn{9}{|l|}{ Social grade } \\
\hline Middle class (ABC1) & 1529 & 41 & 1530 & 41 & 1258 & 43 & 1247 & 43 \\
\hline Working class (C2DE) & 2230 & 59 & 2226 & 59 & 1669 & 57 & 1648 & 57 \\
\hline Not specifiedt & 32 & & 32 & & 26 & & 26 & \\
\hline \multicolumn{9}{|l|}{ Smoking status } \\
\hline Never smoked & 2953 & 79 & 2920 & 78 & - & - & - & - \\
\hline Ever smoked & 804 & 21 & 834 & 22 & - & - & - & - \\
\hline Not specified $t$ & 34 & & 33 & & & & & \\
\hline \multicolumn{9}{|l|}{ Susceptibility } \\
\hline Non-susceptible & - & - & - & - & 2258 & 77 & 2235 & 77 \\
\hline Susceptible & - & - & - & - & 683 & 23 & 673 & 23 \\
\hline Not specifiedt & & & & & 34 & & 33 & \\
\hline \multicolumn{9}{|l|}{ Year } \\
\hline 2011 & 1373 & 36 & 1372 & 36 & 1025 & 35 & 1016 & 35 \\
\hline 2014 & 1205 & 32 & 1203 & 32 & 948 & 32 & 948 & 32 \\
\hline 2016 & 1213 & 32 & 1213 & 32 & 980 & 33 & 980 & 33 \\
\hline
\end{tabular}

*Data are weighted to standardise by age and gender.

tCases excluded due to missing data. 
Table 2 Logistic regression of preban (2011) association between never-smokers' susceptibility to smoke and noticing cigarettes openly displayed and brand awareness, controlling for smoking-related and demographic variables

\begin{tabular}{|c|c|c|c|c|c|}
\hline & \multicolumn{5}{|c|}{$\begin{array}{l}\text { Never-smokers' susceptibility to smoke } \\
1=\text { susceptible }(n=282), 0=\text { not }(n=719)\end{array}$} \\
\hline & $\mathrm{n}$ & $A O R^{*}$ & $\begin{array}{l}95 \% \mathrm{Cl} \\
\text { Lower }\end{array}$ & $\begin{array}{l}95 \% \mathrm{Cl} \\
\text { Upper }\end{array}$ & $P$ value \\
\hline \multicolumn{6}{|c|}{ Any close friends smoke } \\
\hline No & 697 & Ref & & & \\
\hline Yes & 304 & 2.05 & 1.48 & 2.84 & $<0.001$ \\
\hline Any siblings smoke & & & & & $<0.001$ \\
\hline No/No siblings & 836 & Ref & & & \\
\hline Yes & 137 & 2.31 & 1.54 & 3.47 & $<0.001$ \\
\hline $\begin{array}{l}\text { Not sure/not } \\
\text { stated }\end{array}$ & 28 & 2.19 & 0.99 & 4.86 & 0.053 \\
\hline Parents smoke & & & & & 0.283 \\
\hline Neither smokes & 567 & Ref & & & \\
\hline Either & 344 & 1.14 & 0.82 & 1.59 & 0.436 \\
\hline $\begin{array}{l}\text { Not sure/not } \\
\text { stated }\end{array}$ & 90 & 1.48 & 0.90 & 2.44 & 0.121 \\
\hline \multicolumn{6}{|l|}{ Gender } \\
\hline Male & 515 & Ref & & & \\
\hline Female & 486 & 0.93 & 0.69 & 1.24 & 0.617 \\
\hline Age & & & & & 0.026 \\
\hline 11 & 209 & Ref & & & \\
\hline 12 vs 11 & 200 & 1.38 & 0.85 & 2.24 & 0.187 \\
\hline 13 vs $11-12$ & 199 & 1.45 & 0.98 & 2.15 & 0.061 \\
\hline 14 vs $11-13$ & 171 & 1.11 & 0.75 & 1.65 & 0.591 \\
\hline 15 vs $11-14$ & 130 & 1.19 & 0.78 & 1.82 & 0.421 \\
\hline 16 vs $11-15$ & 92 & 0.49 & 0.28 & 0.85 & 0.011 \\
\hline \multicolumn{6}{|l|}{ Social grade } \\
\hline $\begin{array}{l}\text { Middle class } \\
\text { (ABC1) }\end{array}$ & 461 & Ref & & & \\
\hline $\begin{array}{l}\text { Working class } \\
\text { (C2DE) }\end{array}$ & 540 & 0.78 & 0.58 & 1.06 & 0.112 \\
\hline \multicolumn{6}{|c|}{ Notice openly displayed } \\
\hline No or don't know & 195 & Ref & & & \\
\hline Yes & 806 & 1.97 & 1.30 & 2.98 & 0.001 \\
\hline \multirow[t]{2}{*}{ Brand awareness } & 1001 & 1.15 & 1.03 & 1.29 & 0.015 \\
\hline & \multicolumn{5}{|c|}{$\begin{array}{l}\text { Model } \chi^{2}=86.530, \mathrm{df}=14, \mathrm{p}<0.001 \text {. } \\
\text { Hosmer and Lemeshow } \chi^{2}=10.761, \mathrm{df}=8, \mathrm{p}=0.216 \text {. } \\
\text { Cases correctly classified: } 74 \% \text {. } \\
24 \text { cases excluded due to missing data on one or more } \\
\text { independent variables. }\end{array}$} \\
\hline
\end{tabular}

${ }^{*}$ Adjusted for all other variables in the model.

AOR, adjusted OR; ref, reference category.

\section{Preban}

In $2011,28 \%$ of never-smokers $(\mathrm{n}=282)$ were categorised as susceptible. Most never-smokers $(81 \%, n=820)$ noticed cigarette packets displayed at POS, with the mean number of brands recalled less than one $(0.97, \mathrm{SD}=1.26)$. Logistic regression, after controlling for smoking-related and demographic variables, found noticing cigarette packets openly displayed preban to be positively associated with susceptibility (adjusted OR [AOR $]=1.97,95 \%$ CI 1.30 to 2.98; table 2). Additionally, brand recall was also found to have a modest positive association with susceptibility after adjusting for all other variables $(A O R=1.15$, 95\% CI 1.03 to 1.29 ).

\section{Changes in noticing cigarette packs, brand recall and susceptibility from 2011 to 2016}

Table 3 shows how the proportion who noticed cigarette packs at POS, the mean number of cigarette/tobacco brands recalled and the prevalence of susceptibility changed from preban to mid-ban, to postban. Bivariate analyses indicated a decrease in noticing cigarette packets from $81 \%$ preban to $28 \%$ postban $(\mathrm{p}<0.001$ ), a decrease in average brand recall from $0.97(\mathrm{SD}=1.26)$ to 0.69 $(S D=1.09)(p<0.001)$, and a reduction in susceptibility from $28 \%$ preban to $18 \%$ postban $(\mathrm{p}<0.001)$.

Logistic regression, controlling for smoking-related and demographic variables, indicated that the odds of never-smokers noticing cigarette packets at POS decreased following the display ban (table 4). Preban, the odds of never-smokers noticing cigarette packets at POS were more than twice as high compared with mid-ban $(\mathrm{AOR}=2.13,95 \%$ CI 1.73 to 2.63). The odds of noticing cigarette packets at POS reduced further postban $(\mathrm{AOR}=0.20,95 \% \mathrm{CI} 0.16$ to 0.24 ).

Logistic regression, controlling for smoking-related and demographic variables, indicated that susceptibility decreased following the display ban (table 4). Never-smokers in 2011 (preban) had higher odds than never-smokers in 2014 (mid-ban) of being susceptible (AOR $=1.31,95 \%$ CI 1.06 to 1.62), with never-smokers in 2016 (postban) having lower odds of being susceptible than never-smokers in 2014 (AOR $=0.79,95 \% \mathrm{CI}$ 0.63 to 0.99$)$.

\section{Perceptions of, and support for, closed displays}

Most never-smokers at mid-ban $(86 \%, n=783)$ and postban $(90 \%, \mathrm{n}=841)$ indicated that 'Shops should have to keep cigarette packs behind closed shutters' (table 5). Around threequarters at mid-ban $(73 \%, \mathrm{n}=673)$ and postban $(77 \%, \mathrm{n}=688)$ held the view that 'Having cigarette packs behind shutters in shops makes cigarettes seem unappealing', and over four-fifths at mid-ban $(83 \%, n=764)$ and postban $(87 \%, n=790)$ considered that 'Having cigarette packs behind shutters in shops makes me think that it's NOT OK to smoke'.

Table 3 Noticing displays, brand awareness and susceptibility, preban, mid-ban and postban of display

\begin{tabular}{|c|c|c|c|c|c|c|c|}
\hline \multirow[b]{2}{*}{ Base: all never-smokers (weighted) } & \multicolumn{2}{|c|}{ Preban (2011) } & \multicolumn{2}{|c|}{ Mid-ban (2014) } & \multicolumn{2}{|c|}{ Postban (2016) } & \multirow{2}{*}{$\begin{array}{l}\text { P value differences } \\
\text { by year }\end{array}$} \\
\hline & $\mathbf{n}$ & $\%$ & $\mathbf{n}$ & $\%$ & $\mathbf{n}$ & $\%$ & \\
\hline$\%$ Noticing openly displayed at point of sale & 820 & 81 & 613 & 66 & 271 & 28 & $<0.001^{*}$ \\
\hline$\%$ of never-smokers susceptible to smoke & $282^{\mathrm{a}}$ & 28 & $215^{b}$ & 23 & 177 & 18 & $<0.001^{*}$ \\
\hline Mean (SD) number of brands recalled & \multicolumn{2}{|c|}{$0.97(1.26)$} & \multicolumn{2}{|c|}{$0.86(1.28)$} & \multicolumn{2}{|c|}{$0.69(1.09)$} & $<0.001 \dagger$ \\
\hline
\end{tabular}

Number of cases excluded due to missing data: ${ }^{a} n=6 ;{ }^{b} n=6$.

${ }^{*} \chi^{2}$ test for trend.

tOne-way analysis of variance Welch's $F$. 
Table 4 Logistic regression of association between noticing cigarettes displayed and susceptibility, and survey stage, controlling for smokingrelated and demographic variables

\begin{tabular}{|c|c|c|c|c|c|c|c|c|c|c|}
\hline & \multicolumn{5}{|c|}{$\begin{array}{l}\text { Never-smokers noticing openly displayed at point of sale } \\
1=\text { notice }(n=1693), 0=\text { not }(n=1225)\end{array}$} & \multicolumn{5}{|c|}{$\begin{array}{l}\text { Never-smokers' susceptibility to smoke } \\
1=\text { susceptible }(n=673), 0=\text { not }(n=2239)\end{array}$} \\
\hline & $\mathbf{n}$ & $\mathrm{AOR}^{*}$ & $\begin{array}{l}95 \% \mathrm{Cl} \\
\text { Lower }\end{array}$ & $\begin{array}{l}95 \% \mathrm{Cl} \\
\text { Upper }\end{array}$ & $P$ value & $\mathrm{n}$ & $\mathrm{AOR}^{*}$ & $\begin{array}{l}95 \% \mathrm{Cl} \\
\text { Lower }\end{array}$ & $\begin{array}{l}95 \% \mathrm{Cl} \\
\text { Upper }\end{array}$ & $P$ value \\
\hline Survey stage & & & & & $<0.001$ & & & & & $<0.001$ \\
\hline Preban (2011) & 1001 & 2.13 & 1.73 & 2.63 & $<0.001$ & 1001 & 1.31 & 1.06 & 1.62 & 0.014 \\
\hline Mid-ban (2014) & 937 & Ref & & & & 931 & Ref & & & \\
\hline No & 2181 & Ref & & & & 2176 & Ref & & & \\
\hline Yes & 737 & 1.39 & 1.13 & 1.72 & 0.002 & 736 & 2.21 & 1.81 & 2.71 & $<0.001$ \\
\hline Any siblings smoke & & & & & 0.532 & & & & & $<0.001$ \\
\hline No/No siblings & 2425 & Ref & & & & 2424 & Ref & & & \\
\hline Yes & 381 & 1.15 & 0.89 & 1.49 & 0.274 & 380 & 1.62 & 1.26 & 2.07 & $<0.001$ \\
\hline Not sure/not stated & 333 & 1.22 & 0.92 & 1.60 & 0.167 & 329 & 1.72 & 1.30 & 2.28 & $<0.001$ \\
\hline \multicolumn{11}{|l|}{ Gender } \\
\hline Male & 1484 & Ref & & & & 1483 & Ref & & & \\
\hline Female & 1434 & 0.86 & 0.73 & 1.02 & 0.084 & 1429 & 0.84 & 0.70 & 1.01 & 0.058 \\
\hline Age & & & & & 0.207 & & & & & 0.002 \\
\hline 11 & 673 & Ref & & & & 672 & Ref & & & \\
\hline 12 vs 11 & 543 & 1.11 & 0.86 & 1.44 & 0.418 & 541 & 1.06 & 0.79 & 1.42 & 0.704 \\
\hline 13 vs $11-12$ & 528 & 1.21 & 0.96 & 1.54 & 0.111 & 528 & 1.42 & 1.11 & 1.81 & 0.006 \\
\hline 14 vs $11-13$ & 506 & 1.09 & 0.87 & 1.38. & 0.446 & 504 & 1.14 & 0.90 & 1.45 & 0.284 \\
\hline
\end{tabular}

${ }^{*}$ Adjusted for all other variables in the model.

AOR, adjusted OR; ref, reference category.

\section{DISCUSSION}

\section{Main findings}

This study examined the responses of never smoking youth to a POS display ban for tobacco products in the UK. The main findings are that (1) preban, noticing cigarettes displayed at POS and higher brand awareness were positively associated with smoking susceptibility; (2) mid-ban, there was a significant reduction in susceptibility; (3) mid-ban and postban, most young never-smokers were supportive of a display ban; (4) mid-ban and postban, most young never-smokers perceived that the display ban made cigarettes seem unappealing and smoking seem unacceptable; and (5) postban, there were reductions in brand awareness and further reductions in susceptibility.

\section{Interpretation of results}

In the UK smoking prevalence in young people (ages 11-16) had declined significantly in the years preceding the initial wave of this study. Nonetheless, prior to the display ban, we found that a large minority of young never-smokers remained susceptible to smoking. Therefore, preban, the power of the open display of tobacco products is evident, consistent with other studies which have shown associations between POS displays of tobacco and youth susceptibility. ${ }^{45}$ This finding suggests that either noticing cigarettes at POS and higher brand awareness influences susceptibility, or an already present susceptibility influences the noticing of cigarettes and brand awareness. Both directions of association give cause for concern, suggesting that open displays either influence future smoking or that young never-smokers use the display of tobacco products to shape or reinforce their smoking decisions. A display ban is therefore a potential protective factor against any vulnerability to tobacco displays for young never-smokers, who have no existing involvement with the product. As the display ban was phased in, we found a significant decrease in susceptibility from preban to mid-ban, to postban. This is in contrast to results from a study conducted in England which found no reduction in susceptibility; however, that study only covered the period before the full 


Table 5 Perceptions of and support for closed displays, mid-ban and
postban

\begin{tabular}{|c|c|c|c|c|}
\hline \multirow{2}{*}{$\begin{array}{l}\text { Base: all never-smokers } \\
\text { (weighted) }\end{array}$} & \multicolumn{2}{|c|}{ Mid-ban (2014) } & \multicolumn{2}{|c|}{ Postban (2016) } \\
\hline & $\mathrm{n}$ & $\%$ & $\mathrm{n}$ & $\%$ \\
\hline \multicolumn{5}{|c|}{$\%$ of never-smokers who thought*: } \\
\hline $\begin{array}{l}\text { Shops should have to } \\
\text { keep cigarette packs } \\
\text { behind closed shutters. }\end{array}$ & $783+$ & 86 & $841 \ddagger$ & 90 \\
\hline $\begin{array}{l}\text { Having cigarette packs } \\
\text { behind shutters in } \\
\text { shops makes cigarettes } \\
\text { seem unappealing. }\end{array}$ & $673 \S$ & 73 & 6889 & 77 \\
\hline $\begin{array}{l}\text { Having cigarette packs } \\
\text { behind shutters in } \\
\text { shops makes me think } \\
\text { that it's NOT OK to } \\
\text { smoke. }\end{array}$ & $764^{* *}$ & 83 & $790+t$ & 87 \\
\hline
\end{tabular}

*Proportion answering either code ' 1 ' or ' 2 ' (indicating support) to each item. Number of cases excluded due to missing values: $t n=26, \neq n=40, \S n=19,9 n=82$, ${ }^{* *} n=16,+t n=58$.

ban came into force. ${ }^{16}$ The decline in susceptibility reported in our study is likely the cumulative effect of the myriad tobacco control policies introduced in the UK over the last two decades-especially comprehensive controls on other forms of tobacco marketing, for example, the Tobacco Advertising and Promotion Act (TAPA)rather than the display ban in isolation. Nonetheless, our study suggests that the display ban has been an important component of the UK's tobacco control strategy, which has delivered historically low levels of youth smoking. ${ }^{21}$ It was only after the introduction of the display ban that the Youth Tobacco Policy Survey observed the first reduction in smoking susceptibility. Preban this measure had remained constant, with $27 \%$ classified as susceptible in $2008^{22}$ and $28 \%$ in 2011.

The study also points to the power of the brand in recruiting young smokers. Brand awareness and the associated brand imagery is the culmination of the marketing effort and a key promotional driver of consumption, particularly among youth, who are considered most vulnerable. ${ }^{23}$ The lack of familiarity with cigarette brands in 2011, when the mean number of brands recalled was less than one, 0.97 , is likely the result of the TAPA, a comprehensive ban on tobacco advertising, promotion and sponsorship implemented between 2003 and 2005. However, brand recall dropped significantly, to 0.69 postban. Protecting young people from the persuasive power of the brand is an important way of preventing youth smoking. A key strength of a display ban is that it enhances this protection by reducing exposure to the brand.

Our study also highlights the importance of a comprehensive approach to tobacco control. Although a partial ban-as measured at the midpoint of our study when only larger shops had been required to implement the ban-had some benefits, it was only with full implementation in all shops that the policy became fully effective. It is possible that the reductions in susceptibility and brand awareness after full implementation may be due to lagged effects of the ban first implemented in larger shops, or the cumulative effect of the ban in both larger and smaller shops, providing a useful reminder that small shops, such as newsagents and garages, are also important players in youth smoking prevention. ${ }^{15}$

Both mid-ban and postban, young people's attitudes provide additional support for tobacco display bans. While young people perceive open displays as 'cool' and attracting people to smoke, this study shows that display bans communicate the message that cigarettes are not an appealing product and that it is not okay to smoke. That $90 \%$ of our postban sample supported closed displays gives the policy a powerful endorsement; it may also be indicative of the denormalisation of tobacco use and the general trend towards more negative attitudes to smoking in the UK. ${ }^{24}$

Finally, an apparent quirk in the data is worth discussing. A relatively high proportion of our sample (28\%) still reported seeing packs at POS postban, consistent with other studies. ${ }^{12} 15$ Two explanations can be posited for this. First, as high levels of retailer compliance have been found with display bans, at least in high-income countries, ${ }^{12} 25-28$ it is possible that participants retain residual memory of displays preban. Alternatively, and perhaps more likely, even with a full display ban, there will be incidental exposure, where children see cigarettes when the shutters are opened, whether to serve tobacco to other customers or for restocking.

\section{Strengths and limitations}

This study extends other work that found an effect of POS display bans on youth smoking rates ${ }^{10-12}$ by also demonstrating a reduction in youth smoking susceptibility among never-smokers during and after implementation. While susceptibility cannot tell us that young never-smokers will definitely go on to smoke, it is a well-validated measure of future smoking intent. ${ }^{20}$ Although the cross-sectional study design cannot demonstrate causality, it nevertheless provides evidence of population-level changes in relevant outcomes during the multiple phases of implementation across the UK. It is likely, however, that other tobacco marketing controls, in addition to policies such as enhanced health warning labels, smoke-free legislation and increased tobacco taxation, may have contributed to these changes. Although the sample age limit is 16, display bans may have also affected older teens and young adults, for example, with declines in smoking rates seen among those aged 18-24 years old in England. ${ }^{29}$ It is possible that the survey administration method may have resulted in social desirability bias. Interviews for all waves were conducted in-home, where a family member may have been present, and participants may have been worried about showing positive perceptions about tobacco. The face-to-face survey attempts to protect participants' privacy, and limit desirability bias, through the use of showcards which enable participants to read responses from the card and give the number which corresponds to their answer. This makes it difficult for anyone else in the room to follow what response has been given. Finally, the exclusion of rural areas and the reliance on non-probability sampling methods for the final stage of sample selection mean that this sample cannot be said to be completely representative of, or absolutely predictive for, all adolescents in the UK. However, the sample is large enough to be strongly indicative of the complete UK adolescent population, and it is useful to examine results from the sample to gain insight into likely patterns of associations in the population of adolescents in relation to susceptibility to smoke.

\section{CONCLUSIONS}

Both partial and full implementation of a display ban in the UK were followed by a reduction in smoking susceptibility among adolescents. This may be related to the decrease in brand awareness which occurred alongside implementation of the display ban. This suggests that placing tobacco out of sight helps safeguard young people and justifies this policy approach in the UK and elsewhere. It will be important to continue to monitor these measures over time, particularly to see any further impacts alongside the full implementation of standardised packaging in the UK in May 2017, which further restricts the ability of tobacco companies to advertise their brands and communicate positive messages to youth. 


\section{What this paper adds}

\section{What is already known on this subject}

- In countries that have introduced tobacco advertising and promotion bans, showcasing tobacco products at the point of sale (POS) has become more important for tobacco companies.

- Studies have shown positive associations between POS displays and increased smoking, smoking susceptibility and positive attitudes among youth.

What important gaps in knowledge exist on this topic

- Evidence on the impact of a display ban on youth before, during and after implementation is lacking.

- There is limited knowledge on youth support for a display ban, and perceived appeal of cigarettes and acceptability of smoking as a result of closed displays.

\section{What this paper adds}

- Preban, noticing cigarettes displayed at POS and higher brand awareness were associated with smoking susceptibility.

- Implementation of a display ban was followed by reductions in smoking susceptibility and cigarette brand awareness among youth.

- Young never-smokers' support for a display ban was very high mid-ban and postban, and closed displays were perceived to make cigarettes seem unappealing and smoking seem unacceptable.

Correction notice Please note this article has been updated since it was published Online First. The license was updated from CC-BY-NC to CC-BY.

Acknowledgements The authors would like to thank their late colleague $\mathrm{Dr}$ Lynn MacFadyen for her contribution to the development and design of the Youth Tobacco Policy Survey, Dr Catherine Best for providing advice on analysis, and FACTS International for undertaking the fieldwork.

Contributors AF and AMM conceived the paper and designed the study. AMM prepared and analysed the data. AF, AMM and MAGK drafted the manuscript. CM, $L B, G B H$ and MAGK contributed to the interpretation of data and critically revised the manuscript at various stages. All authors read and approved the final version.

Funding This work was supported by grants from Cancer Research UK (C312/ A8721, C312/A15192, C8656/A20456). The funder had no role in study design; in the collection, analysis and interpretation of data; in the writing of the paper; or in the decision to submit the paper for publication.

\section{Competing interests None declared.}

Patient consent for publication Not required.

Ethics approval Ethical approval was granted by the University of Stirling Participants and their parents/guardians gave informed consent before taking part.

Provenance and peer review Not commissioned; externally peer reviewed.

Data sharing statement No additional data are available.

Open access This is an open access article distributed in accordance with the Creative Commons Attribution 4.0 Unported (CC BY 4.0) license, which permits others to copy, redistribute, remix, transform and build upon this work for any purpose, provided the original work is properly cited, a link to the licence is given, and indication of whether changes were made. See: http://creativecommons.org/ licenses/by/4.0/.

\section{ORCID iDs}

Allison Ford http://orcid.org/0000-0002-3624-6673

Crawford Moodie http://orcid.org/0000-0002-1805-2509

Mirte A G Kuipers http://orcid.org/0000-0002-8133-1834

\section{REFERENCES}

1 Joossens LR M. The Tobacco Control Scale 2016 in Europe. Brussels: Association of European Cancer Leagues, 2017.

2 Dewhirst T. POP goes the power wall? taking aim at tobacco promotional strategies utilised at retail. . BMJ Publishing Group Ltd, 2004: 13. 209-10.

3 Lavack AM, Toth G. Tobacco point-of-purchase promotion: examining tobacco industry documents. Tob Control 2006;15:377-84.

4 Robertson L, Cameron C, McGee R, et al. Point-of-sale tobacco promotion and youth smoking: a meta-analysis. Tob Control 2016;25:e83-9.

5 Paynter J, Edwards R. The impact of tobacco promotion at the point of sale: a systematic review. Nicotine Tob Res 2009;11:25-35.

6 Brown A, Moodie C. Adolescents' perceptions of tobacco control measures in the United Kingdom. Health Promot Pract 2012;13:41-7.

7 Chapman S, Freeman B. Regulating the tobacco retail environment: beyond reducing sales to minors. BMJ Publishing Group Ltd, 2009.

8 He Y, Shang C, Huang J, et al. Global evidence on the effect of point-of-sale display bans on smoking prevalence. Tob Control 2018;27:e98-104.

9 Ollila H. Best practices on implementation of the tobacco advertising and display ban at point of sale (Article 13 of the WHO FCTC), A four-country study: Ireland, Norway, Finland and the United Kingdom. Geneva: World Health Organization Framework Convention on Tob Control;; 2020: 348-56.

10 Van Hurck MM, Nuyts PAW, Monshouwer K, et al. Impact of removing point-of-sale tobacco displays on smoking behaviour among adolescents in Europe: a quasiexperimental study. Tob Control 2019;28:401-8.

11 Dunlop S, Kite J, Grunseit AC, et al. Out of sight and out of mind? evaluating the impact of point-of-sale tobacco display bans on smoking-related beliefs and behaviors in a sample of Australian adolescents and young adults. Nicotine Tob Res 2015;17:761-8.

12 Edwards R, Ajmal A, Healey B, et al. Impact of removing point-of-sale tobacco displays: data from a new Zealand youth survey. Tob Control 2017;26:392-8.

13 McNeill A, Lewis S, Quinn C, et al. Evaluation of the removal of point-of-sale tobacco displays in Ireland. Tob Control 2011;20:137-43.

14 Scheffels J, Lavik R. Out of sight, out of mind? removal of point-of-sale tobacco displays in Norway. Tob Control 2013;22(e1):e37-42.

15 Laverty AA, Vamos EP, Millett C, et al. Child awareness of and access to cigarettes: impacts of the point-of-sale display ban in England. Tob Control 2019;28:526-31.

16 Bogdanovica I, McNeill A, Britton J. Cohort study investigating the effects of first stage of the English tobacco point-of-sale display ban on awareness, susceptibility and smoking uptake among adolescents. BMJ Open 2017;7:e012451.

17 Moodie C, MacKintosh AM, Brown A, et al. Tobacco marketing awareness on youth smoking susceptibility and perceived prevalence before and after an advertising ban. Eur J Public Health 2008;18:484-90.

18 Brown A, Moodie C. The influence of tobacco marketing on adolescent smoking intentions via normative beliefs. Health Educ Res 2009;24:721-33.

19 Ford A, MacKintosh AM, Moodie C, et al. Cigarette pack design and adolescent smoking susceptibility: a cross-sectional survey. BMJ Open 2013;3.

20 Pierce JP, Choi WS, Gilpin EA, et al. Validation of susceptibility as a predictor of which adolescents take up smoking in the United States. Health Psychol 1996;15:355-61.

21 Bauld L, MacKintosh AM, Eastwood B, et al. Young people's use of e-cigarettes across the United Kingdom: findings from five surveys 2015-2017. Int J Environ Res Public Health 2017;14. doi:10.3390/ijerph14090973

22 Mackintosh AM, Moodie C, Hastings $\mathrm{G}$. The association between point-of-sale displays and youth smoking susceptibility. Nicotine Tob Res 2012;14:616-20.

23 Ford A, MacKintosh AM, Bauld L, et al. Adolescents' responses to the promotion and flavouring of e-cigarettes. Int J Public Health 2016;61:215-24.

24 Brown A, Moodie C, Hastings G. A longitudinal study of policy effect (smoke-free legislation) on smoking norms: ITC Scotland/United Kingdom. Nicotine Tob Res 2009;11:924-32.

25 Scheffels J, Lavik R. Out of sight, out of mind? removal of point-of-sale tobacco displays in Norway. Tob Control 2013;22:e37-42.

26 Dubray JM, Schwartz RM, Garcia JM, et al. Vendor compliance with Ontario's Tobacco point of sale legislation. Can J Public Health 2009;100:109-12.

27 Zacher M, Germain D, Durkin S, et al. A store cohort study of compliance with a point-of-sale cigarette display ban in Melbourne, Australia. Nicotine Tob Res 2013;15:444-9.

28 Eadie D, Stead M, MacKintosh AM, et al. Are retail outlets Complying with national legislation to protect children from exposure to tobacco displays at point of sale? Results from the first compliance study in the UK. PLoS One 2016;11:e0152178.

29 West R. Smoking in England: latest information on smoking and smoking cessation in England, 2018. Available: www.smokinginengland.info/latest-statistics/ [Accessed 12 Oct 2018]. 